\title{
California in infinite layers
}

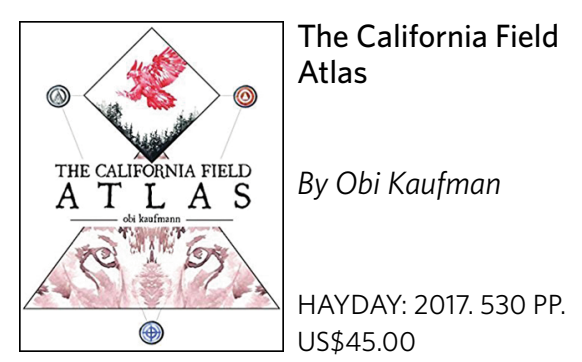

\footnotetext{
T
} he phrase 'coffee table book' can sometimes be an epithet, as if they are more style than substance. Obi Kaufman's hand-drawn and encyclopaedic paean to his home state is perhaps the first book designed to be equally as enjoyed in your living room as in your rucksack as you make your way through the cedars of the Sierra Nevadas, among the Redwoods or across the Mojave scrub of a state that has long been synonymous with ethereal landscapes.

The California Field Atlas may not have a central narrative, preferring instead to have independently structured chapters such as 'Of Earth \& Mountains' and 'Of Fire \& Forests', but the overarching theme that emerges from dipping in and out of the pages is that of one man's quest to capture the nature of this place in as many forms and at as many scales as are imaginable. The hundreds of hand-drawn and illustrated maps, landscapes and portraits of flora and fauna that Kaufman provides here are combined with almost exhaustive facts and emotions (gleaned from a lifetime of hiking, most recently with a company that forages wild materials for colognes and incense) that represent his attempt to convey a sense of place in a multitude of layers: "Every map, every zone can be opened further, explored more, and turned into ten more maps".

The reader who opens the book looking for precise locations and guides to explore the Siskyou forests or a detailed examination of Juniperus californica will be disappointed, and some of the organization and structure in the book can lead to more frustrated searching than reading. These issues can be overlooked, however, given the sheer pleasure of Kaufman's artwork and passion for not only a single place, but also a concept that we can all treasure: geographic literacy. Such a capacity not only enriches us in how we read nature, but also how we imagine and bring that nature into ourselves.

\section{Reviewed by Ryan Scarrow}

Published online: 4 January 2018 https://doi.org/10.1038/s41477-017-0090-9 